\title{
Clinical Application of Bone Marrow Implantation in Patients With Arteriosclerosis Obliterans, and the Association Between Efficacy and the Number of Implanted Bone Marrow Cells
}

\author{
Takashi Saigawa, MD; Kiminori Kato, MD; Takuya Ozawa, MD; Ken Toba, MD*; \\ Yashiro Makiyama, MD; Shiro Minagawa, MD; Shigeo Hashimoto, MD*; Tatsuo Furukawa, MD*; \\ Yuichi Nakamura, MD; Haruo Hanawa, MD; Makoto Kodama, MD; Nobuhiko Yoshimura, MD**; \\ Hiroshi Fujiwara, $\mathrm{MD}^{\dagger}$; Osamu Namura, MD ${ }^{\dagger \dagger}$; Masakazu Sogawa, MD ${ }^{\dagger \dagger}$; \\ Jun-ichi Hayashi, MD ${ }^{\dagger}$; Yoshifusa Aizawa, MD
}

\begin{abstract}
Background There have been a number of recent reports on the use of autologous bone marrow implantation (BMI) in the treatment of peripheral arterial disease, with a clinical response rate of approximately $70 \%$. However, the factors that influence efficacy have not yet been clarified. We have analyzed the relationship between the number of implanted bone marrow cells and the clinical efficacy of BMI.

Methods and Results Eight patients with arteriosclerosis obliterans were treated with BMI. Bone marrow was aspirated from the ilium $(500-1,000 \mathrm{ml})$, the mononuclear cells were separated and then were implanted. The clinical effectiveness of BMI was evaluated by assessing changes in the ankle-brachial pressure index (ABI) and the transcutaneous oxygen pressure $\left(\mathrm{TcO}_{2}\right)$ between the pre-treatment baseline, with follow-up testing at 4 weeks. These changes were defined as $\triangle \mathrm{ABI}$ and $\triangle \mathrm{TcO}$ 2. The mean number of $\mathrm{CD} 34$-positive cells was $1.04 \pm 0.60 \times$ $10^{6} / \mathrm{kg}$ body weight. There was a strong correlation between the number of CD34-positive cells and $\Delta \mathrm{ABI}$ $(\mathrm{r}=0.754, \mathrm{p}=0.028)$.

Conclusions It is likely that the number of implanted CD34-positive cells is one of the primary factors that influence the clinical efficacy of BMI. (Circ J 2004; 68: 1189-1193)
\end{abstract}

Key Words: Angiogenesis; Arteriosclerosis obliterans; Bone marrow implantation; CD34-positive cells; Mononuclear cells

I $\mathrm{n}$ adults, the neovascularization that has been observed in injured tissue, cancer and in the endometrium has been thought to be due to angiogenesis, that is those new vessels arise from existing vessels in the tissue through budding and elongation. Asahara et al have recently shown that endothelial progenitor cells (EPC) are regularly found circulating in adult human blood and that these cells have a role in neovascularization through the process of "vasculogenesis"! Bone marrow-derived smooth muscle cell-like cells were recently reported and a new concept of common vascular progenitors has been proposed that differentiates vascular endothelial cells and smooth muscle cells? The rate of vasculogenesis in new vessels in an animal model was estimated to be about $10 \%$ ? In this model, EPC that had been harvested from bone marrow were injected into an ischemic limb in order to augment angiogenesis and vasculogenesis. Matsubara et al have used this bone marrow

(Received April 26, 2004; revised manuscript received August 27, 2004; accepted September 22, 2004)

Divisions of Cardiology, *Hematology, **Radiation oncology, ${ }^{*}$ Dermatology, and Thoracic and Cardiovascular Surgery, Niigata University Graduate School of Medical and Dental Sciences, Niigata, Japan

Mailing address: Kiminori Kato, MD, Divisions of Cardiology, Niigata University Graduate School of Medical and Dental Sciences, 1-754 Asahimachi, Niigata-City, Niigata 951-8510, Japan. E-mail: kkato48@med.niigata-u.ac.jp implantation (BMI) technique in humans with peripheral arterial disease and have had some success in reducing ischemic symptoms. However, as yet there have not been any reports on the relationship between the number of implanted cells and the effects of BMI. Since mononuclear cells and CD34-positive cells affect the number of EPC, which play a major role in revascularization, it is likely that there is a direct relationship between the number of mononuclear cells or CD34-positive cells and the clinical efficacy of BMI.

In the present study, we have assessed the degree of CD34-positivity in the implanted bone marrow mononuclear cells, and have correlated the total number of mononuclear cells and CD34-positive cells with the clinical efficacy of BMI.

\section{Methods}

\section{Patients}

The entry criteria for patients to be enrolled in the present study were that they had symptoms of chronic limb ischemia, including severe intermittent claudication, rest pain or non-healing ischemic ulcers, but were not considered to be suitable candidates for non-surgical or surgical revascularization. Patients with poorly controlled diabetes mellitus (hemoglobinA $1 \mathrm{c}>6.5 \%$ and proliferative retinopathy) or with evidence of a malignant disorder during the 
Table 1 Profiles of Patients Treated With Bone Marrow Implantation

\begin{tabular}{|c|c|c|c|c|c|c|c|c|c|c|}
\hline Case & Gender & Age & Diagnosis & Implanted lesion & Fontaine & Previous therapy & Hypertension & Dyslipidemia & $D M$ & CRF on $H D$ \\
\hline 1 & $M$ & 79 & $A S O, D M$ & Rt $L / E$ & 3 & Amputation of $L t L / E$ & Yes & No & Yes & No \\
\hline 2 & $F$ & 62 & $A S O, D M, C R F$ on $H D$ & Lt L/E & 4 & Amputation of Rt $L / E$ & Yes & Yes & Yes & Yes \\
\hline 3 & $M$ & 48 & $A S O, D M, C R F$ on $H D$ & Rt $L / E$ & 4 & Amputation of $L t L / E$ & Yes & Yes & Yes & Yes \\
\hline 4 & $M$ & 54 & $A S O, D M, C R F$ on $H D$ & Lt $L / E$ & 4 & Bypass graft & Yes & Yes & Yes & Yes \\
\hline 5 & $M$ & 67 & $A S O, D M$ & Rt $L / E$ & 4 & Medication & Yes & Yes & Yes & No \\
\hline 6 & $M$ & 52 & $A S O, D M$ & Rt $L / E$ & $2 B$ & Medication & Yes & Yes & Yes & No \\
\hline 7 & $M$ & 69 & ASO & Lt $L / E$ & 4 & PTA & Yes & No & No & No \\
\hline \multirow[t]{2}{*}{8} & $M$ & 68 & ASO & Lt $L / E$ & 3 & Bypass graft & Yes & No & No & No \\
\hline & & $62.4 \pm 10.4$ & & & & & $100.0 \%$ & $63.0 \%$ & $75.0 \%$ & $37.5 \%$ \\
\hline
\end{tabular}

M, male; F, female; ASO, arteriosclerosis obliterans; DM, diabetes mellitus; $C R F$, chronic renal failure; HD, hemodialysis; Lt, left; Rt, right; L/E, lower extremity; PTA, percutaneous transluminal angioplasty.

Table 2 Summary of Clinical Effect by Bone Marrow Implantation

\begin{tabular}{|c|c|c|c|c|c|c|c|c|c|}
\hline Case & Gender & Age & $\begin{array}{l}B M-M N C \\
\left(\times 10^{7} / \mathrm{kg}\right)\end{array}$ & $\begin{array}{c}\text { CD34 cells } \\
\left(\times 10^{6} / \mathrm{kg}\right)\end{array}$ & $\begin{array}{c}\text { CD34 rate } \\
(\%)\end{array}$ & $\begin{array}{c}\text { Change of } A B I \\
(\triangle A B I)\end{array}$ & $\begin{array}{l}\text { Change of } \mathrm{TcO}_{2} \\
(\mathrm{mmHg})\left(\Delta \mathrm{TcO}_{2}\right)\end{array}$ & Clinical symptom & $D S A$ \\
\hline 1 & $M$ & 79 & 8.15 & 1.87 & 2.29 & $\begin{array}{c}0.23 \rightarrow 0.39 \\
\quad(0.16)\end{array}$ & $\begin{array}{c}24 \rightarrow 33 \\
\quad(7)\end{array}$ & Relief of pain on walking & No change \\
\hline 2 & $F$ & 62 & 3.09 & 0.74 & 2.39 & $\begin{array}{c}1.32 \rightarrow 1.35 \\
(0.03)\end{array}$ & $\begin{array}{c}24 \rightarrow 19 \\
(-15)\end{array}$ & Healing of ulcer & Increase of small blood vessels \\
\hline 3 & $M$ & 48 & 7.42 & 1.79 & 2.41 & $\begin{array}{c}0.75 \rightarrow 0.94 \\
\quad(0.19)\end{array}$ & $\begin{array}{l}40 \rightarrow 46 \\
(6)\end{array}$ & Decrease in dissection size of foot & Increase of small blood vessels \\
\hline 4 & $M$ & 54 & 6.61 & 1.24 & 1.88 & $\begin{array}{c}0 \rightarrow 0 \\
(0)\end{array}$ & $\begin{array}{c}10 \rightarrow 40 \\
(30)\end{array}$ & Relief of rest pain & Increase of small blood vessels \\
\hline 5 & $M$ & 67 & 5.95 & 0.96 & 1.61 & $\begin{array}{l}0.32 \rightarrow 0.31 \\
\quad(-0.01)\end{array}$ & $\begin{array}{l}0 \rightarrow 21 \\
(21)\end{array}$ & Partial healing of ulcer & Increase of small blood vessels \\
\hline 6 & $M$ & 52 & 5.98 & 1.17 & 1.96 & $\begin{array}{c}0.85 \rightarrow 0.97 \\
(0.12)\end{array}$ & $\begin{array}{c}12 \rightarrow 47 \\
(35)\end{array}$ & Pain-free walking time: $4^{\prime} 00^{\prime \prime} \rightarrow 7^{\prime} 00^{\prime \prime}$ & Increase of small blood vessels \\
\hline 7 & $M$ & 69 & 4.69 & 0.30 & 0.64 & $\begin{array}{c}0.85 \rightarrow 0.89 \\
\quad(0.04)\end{array}$ & $\begin{array}{c}0 \rightarrow 0 \\
(0)\end{array}$ & No change of ulcer & No change \\
\hline 8 & $M$ & 68 & 6.43 & 0.28 & 0.44 & $\begin{array}{c}0 \rightarrow 0 \\
(0)\end{array}$ & $\begin{array}{c}37 \rightarrow 49 \\
(12)\end{array}$ & Pain-free walking time: $5^{\prime} 30^{\prime \prime} \rightarrow 8^{\prime} 30^{\prime \prime}$ & Increase of small blood vessels \\
\hline
\end{tabular}

The values of $\mathrm{ABI}$ and $\mathrm{Tc}_{2} \mathrm{O}_{2}$ were measured before treatment and 4 weeks after treatment.

$\mathrm{TcO}_{2}$, transcutaneous oxygen; DSA, digital subtraction angiongraphy.

previous 5 years were excluded. We obtained written informed consent from all patients. Prior to the commencement of the present study, the protocol had been approved by the ethics committees of all the participating universities.

\section{Procedures}

The primary focus of the clinical trial was the safety and efficacy of the treatment, as defined by an improvement in ankle-brachial pressure index (ABI), transcutaneous oxygen pressure $\left(\mathrm{TcO}_{2}\right)$, and symptoms such as rest pain, pain-free walking, and skin ulceration. Under general anesthesia, between 500 and $1,000 \mathrm{ml}$ of bone marrow was collected from each patient. The mononuclear cells were separated to 95\% purity using a CS3000-Plus blood-cell separator (Baxter, Deerfield, USA) and were concentrated to produce a final volume of about $50 \mathrm{ml}$. The cells were implanted into the ischemic leg by means of an intramuscular injection within $3 \mathrm{~h}$ of the marrow collection. Clinical data were obtained weekly for the first month of treatment and thereafter every 4 months. The $\mathrm{ABI}, \mathrm{TcO}_{2}$, and pain-free walking time (on a treadmill at $3 \mathrm{~km} / \mathrm{h}$ with no incline) were monitored. The Doppler-derived arterial segmental pressures in the ankle and the brachium were measured using a standard adult cuff, and the ABI was defined as the ratio of ankle systolic pressure to brachial systolic pressure (normal value $>1.0)$. . The $\mathrm{TcO}_{2}$ was measured in a supine position using an Oxymonitor (PO-850, Sumitomo-Hightechs, Tokyo, Japan) (normal value $>60 \mathrm{mmHg}$ ) 5 The $\Delta \mathrm{ABI}$ and $\Delta \mathrm{TcO}_{2}$ were defined as the change in $\mathrm{ABI}$ or $\mathrm{TcO}_{2}$ between the pre-treatment measurement and that obtained 4 weeks after treatment. Digital subtraction angiography was also performed 1 week before and 4 weeks after treatment. Throughout the present study, the amount and injection velocity of the contrast medium and the position of the catheter tip, were strictly controlled. The degree of collateral vessel formation was assessed by 2 radiologists and a vascular surgeon, who were not otherwise involved in the study and who were not able to access other information about study participants.

\section{Statistical Analysis}

Changes in the variables measured were analyzed using a paired t-test, and the degree of correlation was assessed using Pearson's correlation coefficient and Fisher's Z-transformation test. Results were expressed as the mean $\pm S D$, and were considered to be statistically significant when the value of $\mathrm{p}$ was less than 0.05 .

\section{Results}

The profiles of the 8 patients treated with BMI and the clinical effects are shown in Tables 1 and 2, respectively. The mean numbers of implanted mononuclear cells and CD34-positive cells were $6.04 \pm 1.58 \times 10^{7} / \mathrm{kg}$ and $1.04 \pm$ $0.60 \times 10^{6} / \mathrm{kg}$, respectively. An improvement in symptoms, such as relief of rest pain or healing of ulceration, was observed in all the patients. Digital subtraction angiographies showed an increase of small blood vessels in 6 of the 
(A)

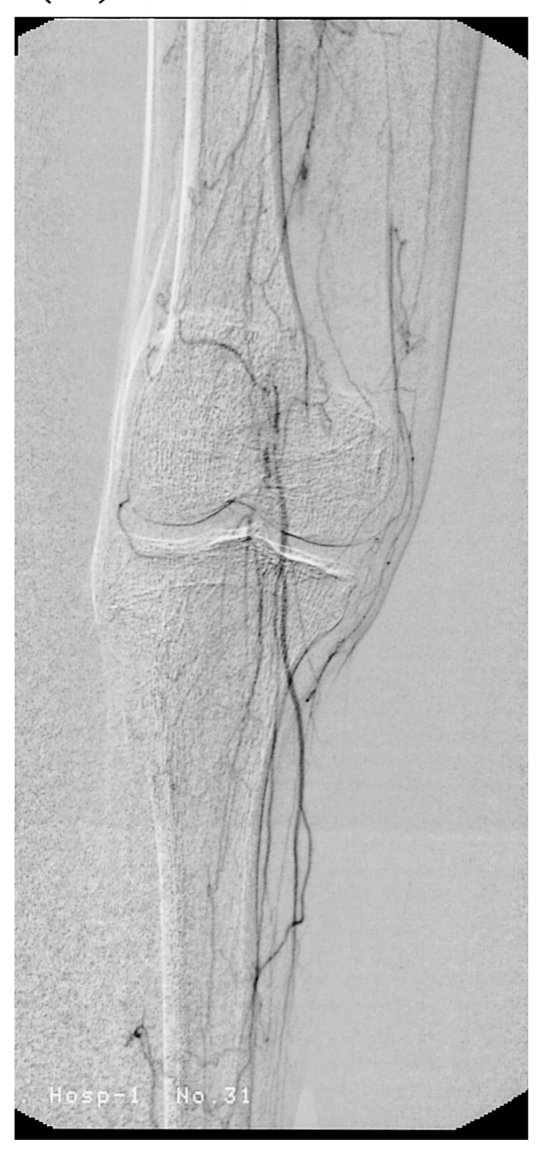

(B)

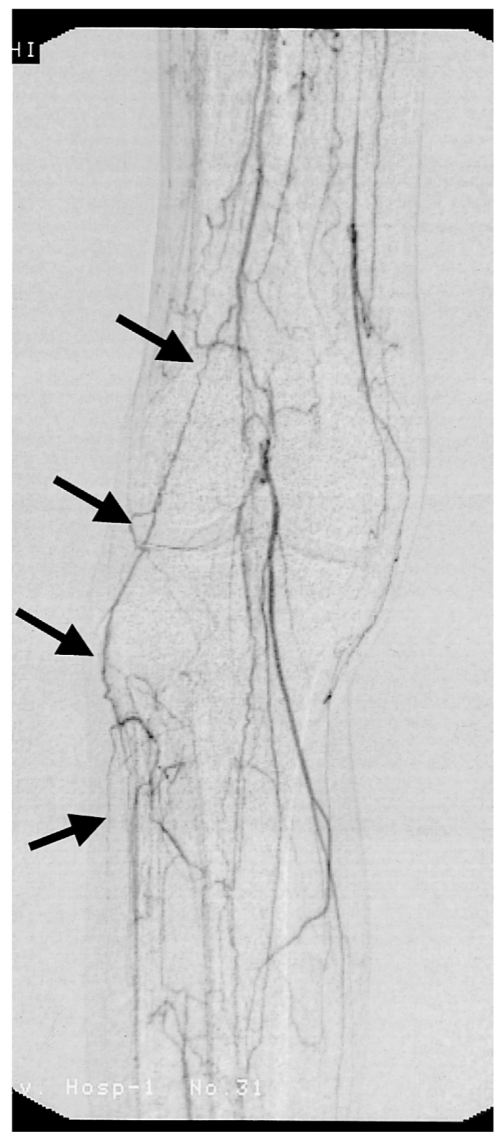

Fig 1. Representative angiography of collateral vessel formation. Collateral branch (indicated by arrows) were strikingly increased in the knee and upper-tibia after marrow implantation (A, before implantation; B, 4 weeks after implantation).

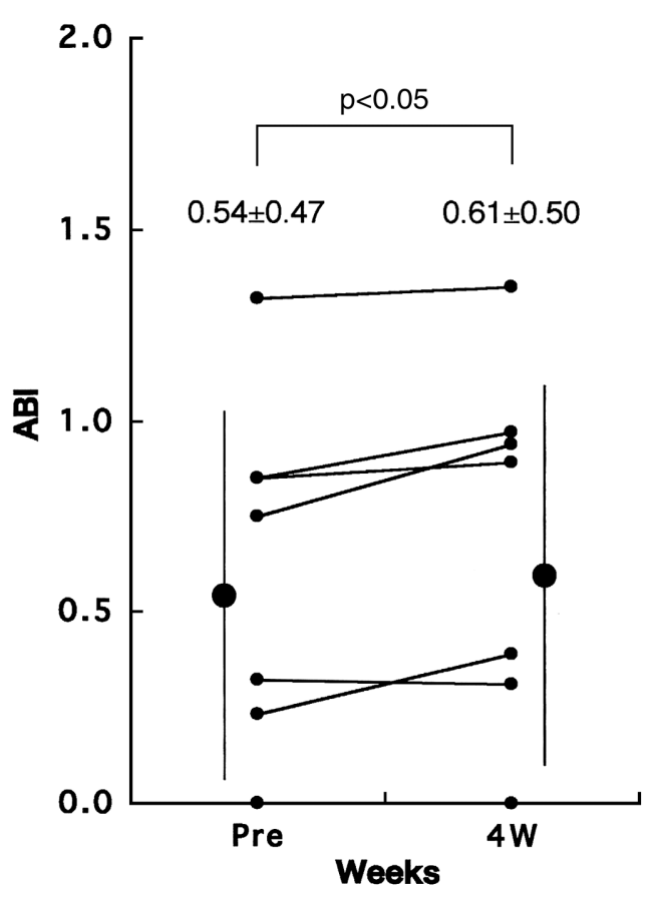

Fig 2. Improvement of ABI after BMI treatment. ABI: ankle brachial pressure index, BMI: autologous bone marrow implantation.

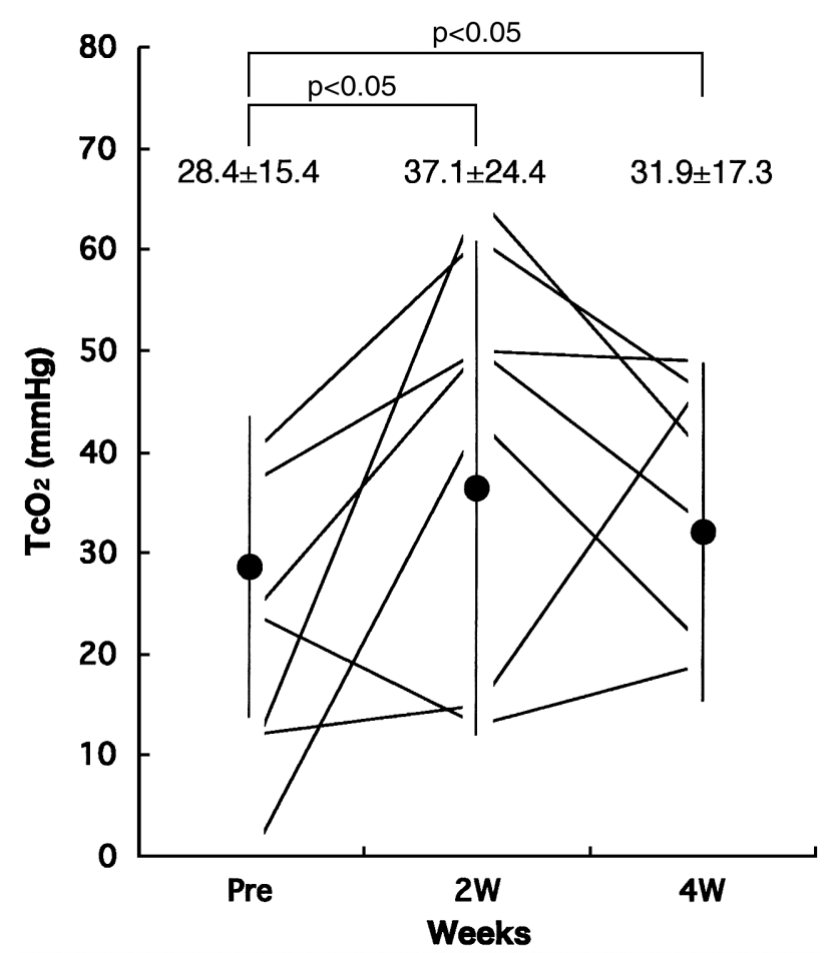

Fig 3. Improvement of $\mathrm{TcO}_{2}$ after BMI treatment. ABI: ankle brachial pressure index, BMI: autologous bone marrow implantation. 
(A)

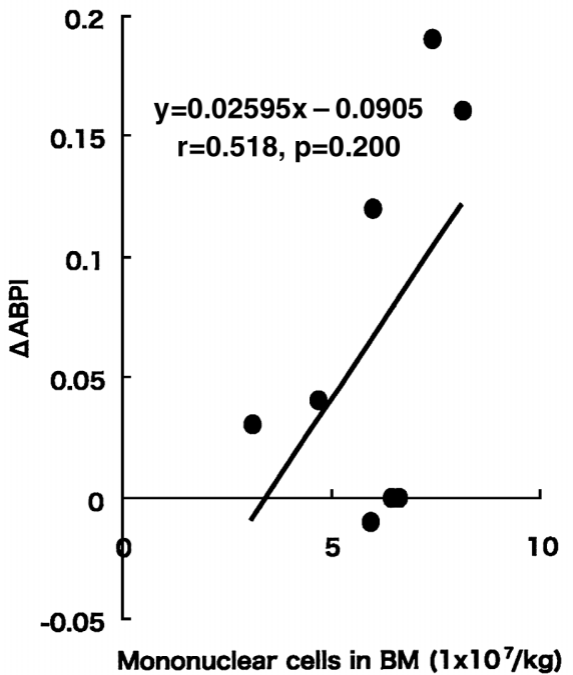

(A)

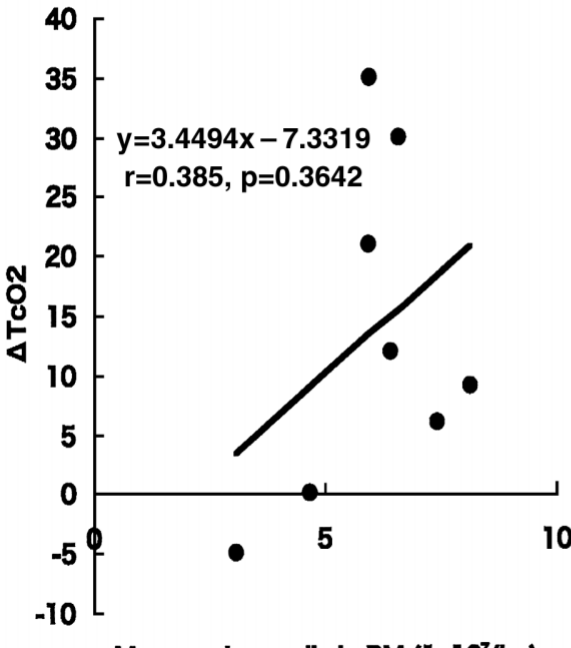

Mononuclear cells in BM (1x107/kg)
(B)

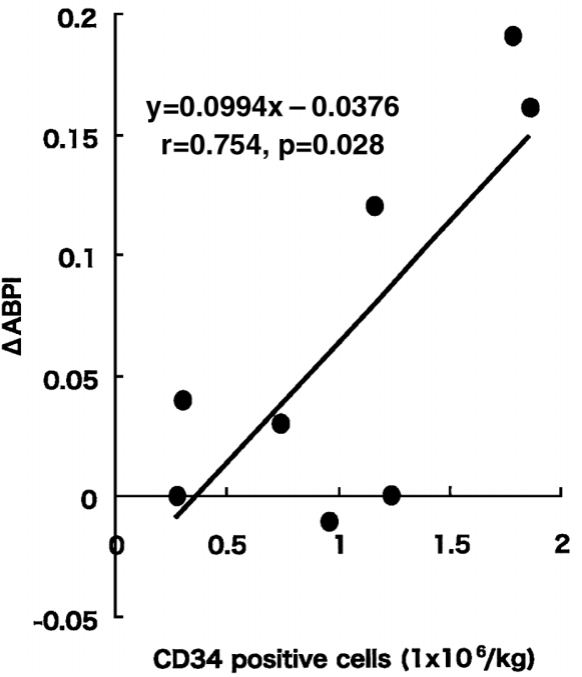

Fig 4. The association between number of cells and the effect of BMI on $\triangle \mathrm{ABI}$. (A) The association between bone marrow $(\mathrm{BM})$ mononuclear cell number and $\triangle \mathrm{ABI}$. (B) The association between number of bone marrow CD34positive cell and $\triangle \mathrm{ABI}$. $\triangle \mathrm{ABI}$ is defined as the change in ankle brachial pressure index between the baseline measurement and that obtained 4 weeks after treatment.
(B)

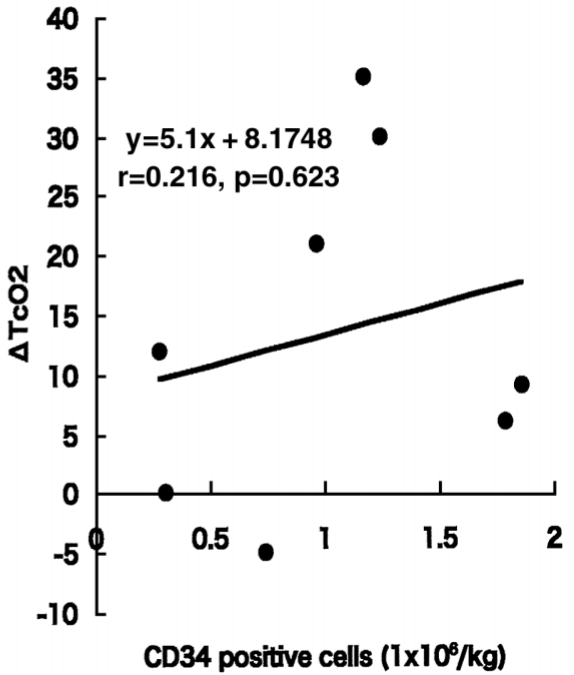

Fig 5. The association between number of cells and the effect of BMI on $\Delta \mathrm{TcO}_{2}$. (A) The association between number of bone marrow mononuclear cells and $\Delta \mathrm{TcO}_{2}$. (B) The association between bone marrow CD34-positive cell number and $\Delta \mathrm{TcO}_{2} . \Delta \mathrm{TcO}_{2}$ is defined as the change in the transcutaneous oxygen pressure between the baseline measurement and the measurement at 4 weeks after treatment.
8 patients (Fig 1). Four weeks after treatment, the mean ABI increased from $0.54 \pm 0.47$ to $0.61 \pm 0.50$ ( $p<0.05$, Fig 2$)$. The $\mathrm{TcO}_{2}$ also increased from $28.4 \pm 15.4 \mathrm{mmHg}$ to $37.1 \pm$ $24.4 \mathrm{mmHg}$ at 2 weeks after treatment $(\mathrm{p}<0.05)$, and a further increase to $31.9 \pm 17.3 \mathrm{mmHg}$ was found at 4 weeks $(\mathrm{p}<0.05$, Fig 3$)$. As shown in Fig $4(\Delta \mathrm{ABI})$ and Fig 5 $\left(\Delta \mathrm{TcO}_{2}\right)$, there was a significant correlation between the number of CD34-positive cells and $\triangle \mathrm{ABI}(\mathrm{p}<0.05)$.

\section{Discussion}

Initially, gene and cell therapy were novel therapeutic options, but these have now become reality. When this type of therapy is used for peripheral arterial disease, Isner has described it as "therapeutic angiogenesis". Gene therapy using vascular endothelial growth factor (VEGF) has been assessed in a small open-label phase I study and was initially found to be successfull, 8 However, a subsequent randomized placebo-controlled trial was unable to confirm the effectiveness of VEGF therapy? The regeneration of blood vessels may be influenced by a number of factors and involve several steps. It is therefore likely that it is not a single factor, but a combination of individual growth factors and cytokines that are required for the coordinated growth of new vessels. For example, angiopoietin 1 (Ang-1) and angiopoietin 2 (Ang-2) have an integrated role in angiogenesis, with the sprouting and elongation of the endothelium being dependent on a higher concentration of Ang-2 compared with Ang-1. A subsequent switch in this balance, with an increase in Ang-1 compared to Ang-2, promotes the alignment of the new endothelium alongside the mural cells during maturation. However, the development of cell therapy may be able to supersede the complex strategy that is required in combination gene therapy. In BMI, supplied cells include not only stem cells and precursor cells as a source of regenerating tissue, but also accessory cells that support angiogenesis and vasculogenesis by producing several growth factors and cytokines in situ. The CD34-negative cells and non-EPC that are included in the bone marrow aspirate, and are subsequently implanted, produce several angiogenic factors such as VEGF, basic fibroblast growth factor, and Ang-1!0 In vitro, vasculogenesis from purified CD34-positive cells was supported and augmented by the addition and co-culture of the cells with 
a CD34-negative bone marrow fraction. On the basis of this finding, it is likely that the intercellular communication between EPCs and accessory cells is important in the process through which EPC differentiate and develop into physiological vascularization! Hence, BMI cell therapy is considered to be an in vivo therapy with EPC-implantation in combination with cytokine administration.

In recent reports from a number of institutions, a variety of different approaches have been suggested for the use of stem cell implantation in the treatment of peripheral ischemic disease. These approaches have included the implantation of bone-marrow-derived mononuclear cells (BM-MNC), CD34-positive cells purified from bone marrow cells, peripheral blood mononuclear cells (PB-MNC), and CD34-positive cells from blood. The effect of PBMNCs is controversial. Matsubara et al have shown that implantation of PB-MNCs is less effective, presumably due to the low frequency of CD34-positive cells in peripheral blood, where the prevalence is approximately 500-fold lower than BM-MNC4 In contrast, the angiogenic effect of PB-MNC implantation was more than a half $(72 \%)$ of the effect of BM-MNC in an in vivo animal model, despite the conclusive difference in the CD34-positive rate (CD34positive cells in BM-MNC and $\mathrm{PB}-\mathrm{MNC}$ are $2.4 \%$ and $0.02 \%$, respectively) $!^{11}$ Hence, when PB-MNC and BMMNC are compared, a CD34-positive rate is not crucial and the angiogenic effect of BMI may arise due to angiogenic cytokine-production in accessory cells in BM-MNC rather than implanted CD34-positive cells. It is also noted that endothelial cells develop from bone marrow monocytic cells through "trans-differentiation" more efficiently than from CD34-positive cells through maturation ${ }^{13}$ In the present study, we have shown that the number of implanted $\mathrm{CD} 34$-positive cells, but not the total MNC, is one of the principal factors that influence the efficacy of BMI. The $\mathrm{CD} 34$-positive rate in bone marrow aspirate is 1.5 to $2.5 \%$ of total nucleated cells and 2 to $3 \%$ of MNC, while that in implanted BM-MNC was 0.4 to $2.4 \%$ (Table 2). Bone marrow cells are generally diluted by peripheral blood cells in the bone marrow collection procedure; hence the CD34positive rate is also an indicator of bone marrow purity in implanted cells. Therefore, implanted cytokine-producing accessory cells also correlate with total implanted CD34positive cells. Bone marrow consists of hematopoietic cells, stem cells, progenitor cells, and accessory cells producing angiogenic cytokines, so that angiogenic therapy using $\mathrm{BM}-\mathrm{MNC}$ was superior to that using PB-MNC in animal models ${ }^{13,14}$ Also the implanted CD34-positive cell number is an indicator of EPC as well as cytokine-producing accessory cells.

\section{Conclusions}

In summary, BMI was performed in 8 patients with arteriosclerosis obliterans. There was an improvement in symptoms, including $\mathrm{ABI}$ and $\mathrm{TcO}_{2}$ in all these patients.
There was a significant correlation between the number of implanted CD34-positive cells and the efficacy of BMI.

\section{Acknowledgements}

This work was supported by a Grant for Promotion of Niigata University Research Project and a Grant-in-aid from the Ministry of Education, Science and Culture of Japan (No. 16590665).

\section{References}

1. Asahara T, Murohara T, Sullivan A, Silver M, van der Zee R, Li T, et al. Isolation of putative progenitor endothelial cells for angiogenesis. Science 1997; 275: 964-967.

2. Sata M. Molecular strategies to treat vascular diseases: Circulating vascular progenitor cell as a potential target for prophylactic treatment of atherosclerosis. Circ J 2003; 67: 983-991.

3. Crosby JR, Kaminski WE, Schatteman G, Martin PJ, Raines EW, Seifert RA, et al. Endothelial cells of hematopoietic origin make a significant contribution to adult blood vessel formation. Circ Res 2000; 87: 728-730.

4. Tateishi-Yuyama E, Matsubara H, Murohara T, Ikeda U, Shintani S, Masaki $\mathrm{H}$, et al. Therapeutic angiogenesis for patients with limb ischaemia by autologous transplantation of bone-marrow cells: A pilot study and a randomised controlled trial. Lancet 2002; 360: $427-435$.

5. Dormandy JA, Rutherford RB. Management of peripheral arterial disease (PAD). TASC Working Group. TransAtlantic Inter-Society Concensus (TASC). J Vasc Surg 2000; 31: S1-S296.

6. Isner JM, Asahara T. Angiogenesis and vasculogenesis as therapeutic strategies for postnatal neovascularization. J Clin Invest 1999; 103: $1231-1236$.

7. Rajagopalan S, Trachtenberg J, Mohler E, Olin J, McBride S, Pak R, et al. Phase I study of direct administration of a replication deficient adenovirus vector containing the vascular endothelial growth factor cDNA (CI-1023) to patients with claudication. Am J Cardiol 2002; 90: $512-516$.

8. Mohler ER 3rd, Rajagopalan S, Olin JW, Trachtenberg JD, Rasmussen $\mathrm{H}$, Pak R, et al. Adenoviral-mediated gene transfer of vascular endothelial growth factor in critical limb ischemia: Safety results from a phase I trial. Vasc Med 2003; 8: 9-13.

9. Rajagopalan S, Mohler ER 3rd, Lederman RJ, Mendelsohn FO, Saucedo JF, Goldman CK, et al. Regional angiogenesis with vascular endothelial growth factor in peripheral arterial disease: A phase II randomized, double-blind, controlled study of adenoviral delivery of vascular endothelial growth factor 121 in patients with disabling intermittent claudication. Circulation 2003; 108: 1933-1938.

10. Shintani S, Murohara T, Ikeda H, Ueno T, Sasaki K, Duan J, et al. Augmentation of postnatal neovascularization with autologous bone marrow transplantation. Circulation 2001; 103: 897-903.

11. Iba O, Matsubara H, Nozawa Y, Fujiyama S, Amano K, Mori Y, et al. Angiogenesis by implantation of peripheral blood mononuclear cells and platelets into ischemic limbs. Circulation 2002; 106: 20192025.

12. Minamino T, Toko H, Tateno K, Nagai T, Komuro I. Peripheralblood or bone-marrow mononuclear cells for therapeutic angiogenesis? Lancet 2002; 360: 2083-2084.

13. Fujiyama S, Amano K, Uehira K, Yoshida M, Nishiwaki Y, Nozawa $\mathrm{Y}$, et al. Bone marrow monocyte lineage cells adhere on injured endothelium in a monocyte chemoattractant protein-1-dependent manner and accelerate reendothelialization as endothelial progenitor cells. Circ Res 2003; 93: 980-989.

14. Kamihata H, Matsubara H, Nishiue T, Fujiyama S, Amano K, Iba O, et al. Improvement of collateral perfusion and regional function by implantation of peripheral blood mononuclear cells into ischemic hibernating myocardium. Arterioscler Thromb Vasc Biol 2002; 22: $1804-1810$. 